\title{
Intensification of cooling of tubular blown polymeric packing films with the flowing-down liquid film
}

\author{
Ihor Mikulionok ${ }^{1}$, Arkadii Petukhov', \\ Viktor Gapon ${ }^{1}$, Oleksandr Gavva ${ }^{2}$ \\ 1 - National Technical University of Ukraine "Igor Sikorsky Kyiv Polytechnic Institute", \\ Kyiv, Ukraine \\ 2 - National University of Food Technologies, Kyiv, Ukraine
}

\section{Keywords: \\ Packing \\ Polymer \\ Extrusion \\ Film \\ Cooling}

\section{Article history:}

Received

03.07.2018

Received in

revised form

18.09.2018

Accepted

28.09.2018

Corresponding author:

Ihor Mikulionok

E-mail:

i.mikulionok@

kpi.ua

DOI:

10.24263/2304-

974X-2018-7-3-12

\section{Abstract}

Introduction. Analytical and natural researches of process of cooling of a packing film of low density polyethylene (LDPE; high pressure polyethylene) are conducted by the flowing-down water film.

Material and methods. Pilot studies of cooling of the film are conducted at the following parameters: film type - flat; speed of the film $-0.03-0.50 \mathrm{~m} / \mathrm{s}$; sizes of the slot-hole distributor of a water film: slot size $-0.4-0.8 \mathrm{~mm}$, slot width $-300 \mathrm{~mm}$; temperature of the cooling water $-15-40{ }^{\circ} \mathrm{C}$. Rational parameters of process of cooling are determined on the basis of mathematical modeling.

Results and discussion. Parameters of a liquid film change only on an entrance zone and depend on liquid concentration, speed of the polymeric tube and initial distribution of speed of the liquid at the exit from a distributive ring. At high values of liquid concentration (Re $>20000)$ only the wall layer of liquid participates in heat exchange.

For the film from LDPE its external surface hardens at distance about $0.01 \mathrm{~m}$ from the beginning of contact with water, and an internal surface - at distance about $0.10-0.15 \mathrm{~m}$. Therefore the ring for distribution of liquid needs to be established after the termination of a blowing zone of the polymeric tubular workpiece. It is also necessary to provide the steady movement of a continuous liquid film on an external surface of a polymeric tube on length to $0.2 \mathrm{~m}$ from the beginning of contact of liquid from the polymeric film.

Temperature of the cooling water in the range of $20-60{ }^{\circ} \mathrm{C}$ significantly does not influence both intensity of cooling process, and physical-mechanical properties of the produced polymeric film.

For thick films from LDPE (thickness more than $200 \mu \mathrm{m}$ ) and over $1 \mathrm{~m}$ wide intensity of cooling is limited to the critical liquid concentration.

For practical application of the received results the nomogram for determination of volume liquid concentration of the cooling water, and also volume productivity of the technological line depending on the sizes of a ready tubular blown polymeric film is offered.

Conclusion. The scientific value of results consists in definition of rational conditions of application of liquid cooling of the tubular blown polymeric films produced by extrusion. 


\section{Introduction}

Process of cooling of an extruded tubular blown polymeric film significantly influences productivity of the film technological line and quality of the produced product. Due to relative simplicity of constructive and technological realization of process of cooling the air method is the most widespread. However the air method of cooling can not always correspond to high productivity of the basic machine of the film line, namely a screw extruder, especially at production of thick polymeric films [1-4].

It is essential to increase efficiency and intensity of cooling of a polymeric tubular blown polymeric film by means of its interaction with a film of the liquid which is flowing down on its external surface. In this case the method of extrusion of a tubular polymeric film with blowing according to the scheme "from top to down" is the most expedient (unlike air cooling when the scheme "from below up" is the most acceptable).

However for the analysis of efficiency of process of cooling of the tubular blown polymeric film with a gravitational film of liquid it is necessary to investigate hydrodynamics of the liquid film which is flowing down on the moving firm surface and also heat exchange between them.

\section{Literature review and research problems}

The main stages of technology influencing quality of tubular blown polymeric packing films are processes of preparation of polymer melt in an extruder, a blowing of workpiece of the polymeric tubular film at the exit from an extruder die, and also cooling of the overblown polymeric tubular film.

The analysis of publications on a problem of production of tubular blown polymeric films showed that the majority of them is devoted to numerical and experimental modeling of separate stages of process of their production. At the same time the main attention is paid to process of preparation of polymer melt in the extruder [5-9], to process of a shaping of a polymer film bubble (the overblown polymer tubular film) [1], and also process of cooling of the formed polymer film bubble with a stream of air [10].

For example, in work [11] production process, and also rheological properties of fusion and tubular blown films of the polypropylene filled with various nanoparticles are in detail considered. At the same time the formed tubular blown film was cooled on air.

The mathematical model of not isothermal process of a shaping of a tubular blown polymeric film is given in work [12]. The analysis of average temperature of a tubular blown film from the low density polyethylene and axial tension arising in it in the course of a blowing is made. Cooling of a film is considered at its contact with air.

In work [13] properties of a tubular blown film from linear low density polyethylene with an additive of hyperbranched polymer are investigated. The produced films differ in high quality of a surface with high operational properties. The studied films were produced by means of a single screw extruder with a diameter of screw of $25 \mathrm{~mm}$ and the relation of length of the screw to its diameter 25:1. Cooling of a polymer bubble was carried out by an air stream.

Work [14] investigates properties of a tubular blown packing film from polyvinyl acetate with nanoparticles of starch. The polymeric film was made on a single screw extruder with a diameter of screw of $35 \mathrm{~mm}$; screw long 25 times more of its diameter and extent of compression 1:3. The polymer bubble after its blowing was cooled on air.

Features of traditional technology of a tubular blown polymeric film on the basis of 
starch are also considered in works $[15,16]$.

In work [17] process of blowing and dynamics of further destruction of a biodegradable tubular blown polymeric packing film on the basis of low density polyethylene are considered. Cooling of the film after its blowing it is also carried out on air.

Results of research of process of production of a biodegradable tubular blown film, and also physical-mechanical properties of this film are considered in work [18]. Production of the film in this work is also considered by the method "from below up" with cooling of the film on air. Results of similar researches for a biodegradable tubular blown film on the basis of Polylactic acid are given in work [19].

Results of researches of process of orientation at production of tubular blown films from various types of polyethylene are given in work [20]. Anisotropy of the films produced by an extrusion method with their further cooling on air is also considered. Results of similar researches are given also in work [21].

Possibilities of a blowing of tubular films from polyethylene and polypropylene are considered in work [22].

In work [23] rheological aspects of process of a shaping of a polymer bubble with its further cooling on air are in detail investigated.

Similar problems are also considered in works [24-28].

Works $[1,29]$ present results of mathematical modeling of process of cooling of tubular polymeric products in a liquid stream. However the models given in these works are not suitable for the analysis of process of cooling with the flowing-down liquid film.

Directly the problem of cooling of polymeric films is considered in work [30]. However these researches concern cooling to a flat polymeric film on the drum which is partially shipped in a water bath. And results of mathematical modeling of process of cooling of a tubular polymeric film by the flowing-down liquid film are given in work [31]. At the same time the analysis only of results of mathematical modeling of the temperature field of epy polymeric film is made and stability of the polymer bubble and a liquid film in this work were not considered.

The hydrodynamics and heat exchange of the flowing-down water film at its boiling on a motionless vertical surface are investigated in work [32].

The majority of the settlement dependences of process of heat exchange which are available in literature with participation of the flowing-down film of liquid are suitable for motionless horizontal or vertical surfaces [33] that makes impossible carrying out the analysis of process of film cooling for a mobile vertical surface.

As we see, the majority of researches of the last years concern the analysis of properties of new polymeric compositions and films with their use. At the same time results of researches of process of cooling of a tubular polymeric film with the liquid film which is flowing down on it are practically absent. Therefore researches of process of liquid cooling of hose polymeric packing films is actual.

The objective of the study is the analysis of process of cooling of tubular blown polymeric packing films the flowing-down liquid film. It will allow to determine rational parameters of process of cooling (type of cooling liquid, its temperature and a volume discharge, and also cooling zone length) for cooling of a polymeric film up to the required temperature in a definite time.

It is necessary to solve the following tasks to achieve the objective:

- theoretical investigation the liquid concentration size providing a condition of balance of forces, acting on a polymer bubble at its cooling with the flowing-down liquid film; 
- experimentally confirm a possibility of practical realization of process of liquid cooling of tubular blown polymeric films;

- formulate recommendations about rational realization process of cooling of tubular blown polymeric packing films with the flowing-down liquid film.

\section{Materials and methods}

\section{Materials}

As material of the studied polymeric films low density polyethylene (LDPE) of two types was used:

- LDPE, type 1; density is $919.0 \mathrm{~kg} / \mathrm{m}^{3}$; melt flow index of $2 \mathrm{~g} / 10 \mathrm{~min}$ at a temperature of $190{ }^{\circ} \mathrm{C}$ and load of $21.17 \mathrm{~N}$;

- LDPE, type 2; density is $920.5 \mathrm{~kg} / \mathrm{m}^{3}$; melt flow index of $0.3 \mathrm{~g} / 10 \mathrm{~min}$ at a temperature of $190^{\circ} \mathrm{C}$ and load of $21.17 \mathrm{~N}$.

The studied samples of a polymeric film produced the next way.

The film sample by the sizes $1000 \times 320 \times 0.1 \mathrm{~mm}$ (along the polymer bubble) was cut out from the polymer bubble in folded form produced on experimental-industrial working plant. Then the long parties of a sample of the film fixed on a similar film substrate by means of steel wires with a diameter of $0.5 \mathrm{~mm}$. Then the film substrate in horizontal position had on the flat electric heater. In the middle of the made package from one of its short parties between a sample of the film and the film substrate placed jumped to thickness of $0.1 \mathrm{~mm}$ thermojunction. After that at a temperature of $180^{\circ} \mathrm{C}$ the prototype of the film and the film substrate were welded among themselves. As a result received a monofilm 0.2 mm thick with sealed in its center (on thickness) the thermocouple.

Samples of a polymeric film of other thickness were similarly made.

\section{Experimental installation}

Authors developed the experimental stand for research of process of heat exchange at a film current of liquid on a mobile polymeric surface. Also experimental-industrial installation (working plant) was developed for production of a tubular blown polymeric film with liquid cooling on which operating modes of formation of the polymer bubble and a design of the liquid cooling system were fulfilled.

Basic elements of the experimental stand are a head for distribution of the liquid film and the studied flat sample of a polymeric film.

The head is executed in the form of the plane-parallel slot-hole distributor with regulation of distance between sponges (within $0.4 \ldots 0.8 \mathrm{~mm}$ ) and slot of $300 \mathrm{~mm}$ wide. At the same time as cooling liquid the tap water which is previously purified by means of the filter with a temperature of $15 \ldots 40{ }^{\circ} \mathrm{C}$ was used. Regulation of water temperature was carried out by means of the heat exchanger supplied with resistance electric heaters. The volume flow rate of water was regulated the valve, and measured by the rotameter. Also after each experience carried out control measurement of volume of water by a volume method by means of a measured vessel and a stop watch. Water temperature on an entrance and an exit of the studied sample of the polymeric film was measured by the thermocouples installed in the camera of a distributive head and before a reception funnel.

The prototype of the polymeric film with a film substrate the long parties was fixed on 
links of two vertically located infinite chains which covered driving and tension asterisks of the pulling device. At the same time the thermocouple of the film sample was connected to measuring equipment. The run of the film was carried out from the reversive electric motor. The film run in the vertical direction was limited to two limit switches. The working film run - vertical from top to bottom with the regulated speed $(0.03-0.50 \mathrm{~m} / \mathrm{s})$, and idle run from below up with a constant speed.

Heating of the polymeric film prototype was carried out thermal radiation from the thermal screen the size $0.3 \times 1,0 \mathrm{~m}$ supplied with the flat electric heater of resistance. Temperature of the screen was maintained automatically by means of the device of thermal automatic equipment. For providing the "soft" mode of heating of the sample it was carried out not only regulations of power of the electric heater of the screen, and distance between the screen and the sample.

Steel wires at the edges of the double thickness monofilm during experience played a role of peculiar thresholds, providing at the same time a current of the liquid film, uniform on sample width.

Research was conducted in the following sequence.

By means of chains the sample of the polymeric film is established in extreme top point (at the same time the top limit switch works). After that the necessary mode of heating of epy film with the thermal screen before achievement by a sample of epy polymeric film of necessary temperature was provided.

Then the necessary volume flow rate of water of a certain temperature which at the exit from a head in the form of a flat film flew down on the motionless directing plate established under a sample of the polymeric film and at last got to a reception funnel was provided.

After that the drive of the pulling device was switched on. At the same time chains with the set speed moved the polymeric film sample concerning the distributor of a water film, the sample began to contact to water and was gradually cooled, the lower limit switch of the stand did not work yet. During the movement of the studied sample of a polymeric film the thermogram of its cooling continuously registered.

Thus, at the experimental stand it was possible to conduct numerous researches of cooling process of a certain sample of the polymeric film under various conditions: a volume flow rate of the cooling water, its initial temperature, and also speed of the movement of the sample of the polymeric film.

Experimental-industrial installation for production of the tubular blown polymeric film is developed on the basis of the line for production of a tubular blown film according to the scheme "from above-down". Installation consists of a single screw extruder, an extrusive ring die with the central feeding of melt below which the ring for formation of the water film on an external surface of the polymer bubble is located. For elimination of possible cross fluctuations of the polymer bubble below the liquid distributive ring the stabilizing device with system of the rollers made of a polytetrafluorethylene (teflon) which evenly on a circle contact to the bubble is mounted. Under these device it is mounted the putting and pulling devices executed in the form of two cheeks located at an angle to each other and two rubberized rolls, respectively (Figure 1). 


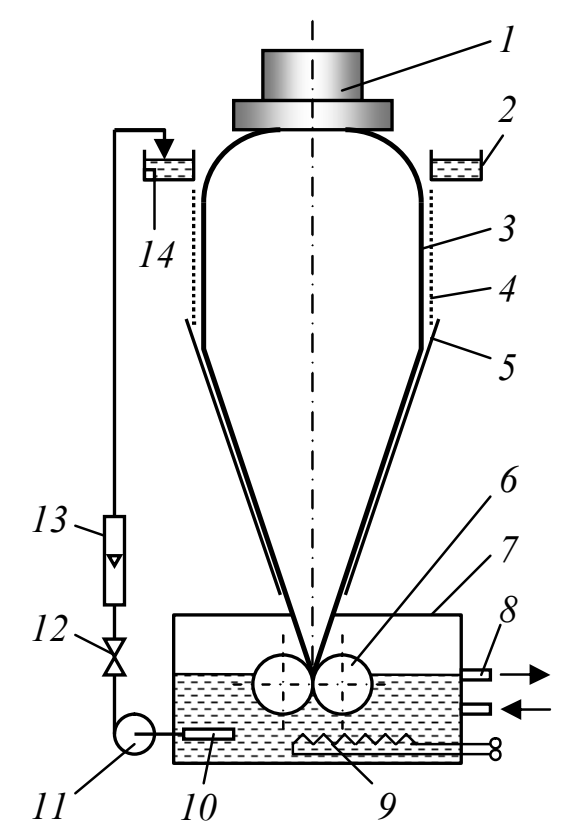

Figure 1. Experimental-industrial installation for production of the tubular blown polymeric film:

1 - extruder ring film die; 2 - the film cooling system with a distributive ring; 3 - tubular blown polymeric film; 4 - film of cooling water; 5 - the putting cheeks; 6 - the pulling rolls; 7 - bathtub for water reception; 8 - drain branch pipe for maintenance of water level in the bathtub; 9 - electrical heater; 10 - filter; 11 - pump; 12 - regulating valve; 13 - rotameter; 14 - resistance thermometer

On the made experimental-industrial installation (working plant) a number of experiments on production of tubular blown films from LDPE in the wide range of values of productivity of the extruder, volume flow rate and reference temperature of the cooling water, and also film thickness depending on conditions of production of the polymeric film was carried out.

\section{Mathematical modeling}

Earlier authors developed mathematical model of process of liquid cooling of the tubular blown polymeric film [31]. This model contains the equations of the movement and continuity for the liquid film current by gravity, the equations of conservation of energy for the polymeric film and the liquid film, and also the corresponding initial and boundary conditions on the speed and temperature.

The developed model allows for the set film speed (extruder productivity) and parameters of the film to determine length of a cooling zone or for the set length of a cooling zone to determine the maximum speed of the film with the set parameters. 


\section{Results and discussion}

\section{Theoretical researches}

For determination of design and technological data of cooling process of the tubular blown polymeric film we will consider balance of forces, acting on the polymer bubble limited to two sections: melt exit section from a ring extrusive die and section through contact of the pulling rolls (Figure 2):

$$
\vec{F}_{0}+\vec{P}+\vec{G}+\vec{P}_{\mathrm{w}}+\vec{F}_{\mathrm{r}}+\vec{F}_{\mathrm{fp}}+\vec{F}_{\mathrm{fw}}=0
$$

where $\vec{F}_{0}$ is the viscoelastic stretching force operating in the bubble basis (it is result of action of other forces applied to the bubble), N; $\vec{P}$ is force from action of pressure of air inside the bubble, N; $\vec{G}$ is weight of the bubble, N; $\vec{P}_{\mathrm{w}}$ is force of a high-speed pressure of a stream of liquid at the exit from the distributing device of a liquid film, N; $\vec{F}_{\mathrm{r}}$ is bubble stretching force from the pulling rolls, $\mathrm{N} ; \vec{F}_{\mathrm{fp}}$ is bubble friction force on cheeks of the putting device, $\mathrm{N} ; \vec{F}_{\mathrm{fw}}$ is friction force between the polymer bubble and a film of liquid, $\mathrm{N}$.

Let's write down dependence (1) in projections to a longitudinal axis of the bubble

$$
F_{0}+P-G-P_{\mathrm{w}} \cos \gamma-F_{\mathrm{r}}+F_{\mathrm{fp}}-F_{\mathrm{fw}}=0 .
$$

Now we will consider each of components of dependence (2).

The viscoelastic stretching force operating on the bubble basis

$$
F_{0}=2 \pi r_{0} \delta_{0} \sigma_{0}
$$

where $r_{0}$ and $\delta_{0}$ are initial radius and initial thickness of the polymeric tubular workpiece (initial polymer bubble) at the exit from the extrusive die, respectively, $\mathrm{m} ; \sigma_{0}$ is the longitudinal tension of stretching in the bubble at the exit from an extrusive die, $\mathrm{Pa}$.

Force from action of pressure of air in the bubble is

$$
P=\pi\left(r_{\mathrm{s}}^{2}-r_{0}^{2}\right) \Delta p
$$

where $\mathrm{r}_{\mathrm{s}}$ is bubble radius after its blowing, $\mathrm{m} ; \Delta p$ - excessive pressure in the bubble, $\mathrm{Pa}$.

The weight of the polymer bubble is equal

$$
G=G_{1}+G_{3}+G_{3},
$$

where $G_{1}$ is weight the bubble on the blowing zone, $\mathrm{N} ; G_{2}$ is weight of the bubble of a cylindrical form on the zone from the place of contact of the bubble with liquid to the zone of folding of the bubble, $\mathrm{N} ; G_{3}$ is bubble weight on the zone from the place of folding of the bubble to the pulling rolls, $\mathrm{N}$. 


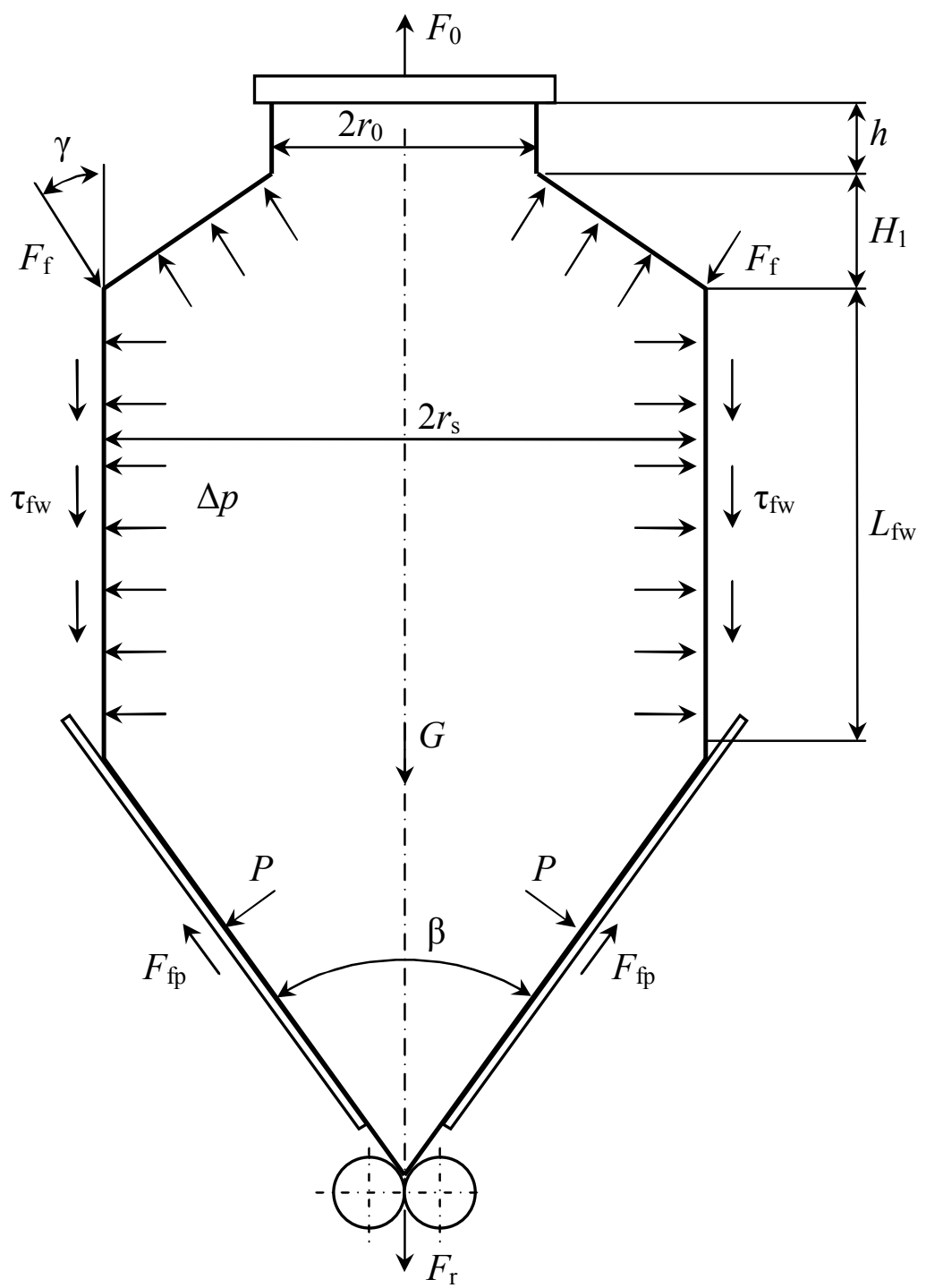

Figure 2. The scheme of forces operating on the polymer bubble at liquid cooling (explanations in the text)

Let's analyze the components of formula (3).

Bubble weight on the blowing zone is [1]

$$
G_{1}=2 \pi r_{0} \delta_{0} \rho g\left(\frac{v_{0}}{v_{\mathrm{s}}-v_{0}}\left(H_{1}-h\right) \ln \frac{v_{\mathrm{s}}}{v_{0}}+h\right),
$$

where $\mathrm{g}$ is acceleration of gravity, $\mathrm{m} / \mathrm{s}^{2} ; v_{0}$ is speed of tubular workpiece at the exit from the extrusive die, $\mathrm{m} / \mathrm{s} ; v_{\mathrm{s}}$ is speed of the formed bubble at the exit from the blowing zone, $\mathrm{m} / \mathrm{s} ; H_{1}$ is 
distance from the beginning of blowing zone prior to contact of the bubble with liquid (the blowing zone), $\mathrm{m} ; h$ is distance from the extrusive die prior to the beginning of blowing zone, $\mathrm{m}$.

Taking into account practice of production of tubular polymeric films their stability during cooling with the film of liquid is maximum in a case when $h=0$. Then dependence (4) takes a form

$$
G_{1}=2 \pi r_{0} \delta_{0} H_{1} \rho g\left(\frac{v_{0}}{v_{\mathrm{s}}-v_{0}} \ln \frac{v_{\mathrm{s}}}{v_{0}}\right)
$$

The weight of the cylindrical part of the bubble on the zone from the place of contact of the bubble with liquid to the zone of folding of the bubble

$$
G_{2}=2 \pi r_{\mathrm{s}} \delta_{\mathrm{s}} \rho g L_{\mathrm{fw}}
$$

where $\delta_{\mathrm{s}}$ is bubble thickness after its blowing, $\mathrm{m}$; $L_{\mathrm{fw}}$ is length of the continuous liquid film flow zone, $\mathrm{m}$.

Bubble weight on the zone from the place of the bubble folding to the pulling rolls

$$
G_{3}=2 \pi r_{\mathrm{s}}^{2} \delta_{\mathrm{s}} \rho g \operatorname{ctg} \frac{\beta}{2}
$$

where $\beta$ is angle of folding of the polymer bubble.

Taking into account expressions (5)-(7) dependence (3) will equal

$$
G=2 \pi r_{0} \delta_{0} H_{1} \rho g\left(\frac{v_{0}}{v_{\mathrm{s}}-v_{0}} \ln \frac{v_{\mathrm{s}}}{v_{0}}\right)+2 \pi r_{\mathrm{s}} \delta_{\mathrm{s}} \rho g\left(L_{\mathrm{fw}}+r_{\mathrm{s}} \operatorname{ctg} \frac{\beta}{2}\right)
$$

Force of a high-speed pressure of a ring liquid stream

$$
P_{\mathrm{w}}=\pi r_{\mathrm{s}} H \rho_{\mathrm{w}} \bar{U}^{2},
$$

where $H$ is width of slot of the distributive ring of liquid, m, $\mathrm{m} ; \rho_{\mathrm{w}}$ is density of liquid, $\mathrm{kg} / \mathrm{m}^{3}$; $\bar{U}$ is average speed of liquid in a point of contact with the polymer bubble, $\mathrm{m} / \mathrm{s}$.

Friction force between the polymer bubble and the liquid film is

$$
F_{\mathrm{fw}}=S_{\mathrm{fw}} \tau_{\mathrm{fw}},
$$

where $S_{\mathrm{fw}}$ is surface area of the polymer bubble length $L_{\mathrm{fw}}$ (from the place of the beginning of contact of the bubble with liquid to the place of a rupture of the continuous ring film of liquid on separate streams), $\mathrm{m} ; \tau_{\mathrm{fw}}$ is tangent tension on contact border "polymer - liquid", $\mathrm{Pa}$

$$
\tau_{\text {wall }}=g \bar{\delta} \rho_{\mathrm{w}}
$$

where $\bar{\delta}$ is average thickness of the liquid film of on the zone of its steady current length $L_{\mathrm{fw}}$, m. 
We will determine the average thickness of the liquid film on the zone by length $L_{\mathrm{fw}}$ from dependence [34]

$$
\bar{\delta}=0,457\left(\frac{v_{w}^{2}}{g}\right)^{\frac{1}{3}}[\operatorname{Re}(1 \pm \Pi)]^{0,36} \quad \text { if } \operatorname{Re}(1 \pm \Pi)>1600
$$

where $v_{\mathrm{w}}$ is kinematic viscosity of liquid, $\mathrm{m}^{2} / \mathrm{s} ; \Pi=U_{0} / \bar{U}-$ the simplex considering the relative speed of the liquid film; $U_{0}$ is speed of the polymer bubble, $\mathrm{m} / \mathrm{s} ; \bar{U}$ is average speed of a current of the liquid film on the zone length $L_{\mathrm{fw}}$, which is equal to the average speed of liquid in a point of initial contact with the polymer bubble, $\mathrm{m} / \mathrm{s}$.

As the volume fluid flow rate is to constants (losses on evaporation in environment we neglect), taking into account expression for irrigation density $\Gamma_{V}=\bar{U} H$ the component of a high-speed pressure takes a form

$$
P_{\mathrm{w}}=\pi r_{\mathrm{s}} b_{\mathrm{w}} \rho_{\mathrm{w}} \bar{U}^{2} \cos \gamma=\frac{\pi r_{\mathrm{s}} \rho_{\mathrm{w}} \Gamma_{V}^{2} \cos \gamma}{H},
$$

where $b_{\mathrm{w}}$ is liquid stream width at the beginning of contact with the bubble, $\mathrm{m}$ (with an accuracy, sufficient for engineering calculations, it is possible to accept that $b_{\mathrm{w}}=H$ ).

Bubble friction force on cheeks of the putting device $F_{\mathrm{fp}}$ depends on pressure in the bubble, coefficient of friction of polymer on material of cheeks at this temperature and the area of contact of the bubble with cheeks.

In the analysis of dependence (2) practical value has a case when polymer melt is extended not by effort from the pulling rolls, and a body weight and force of a high-speed pressure of the liquid stream $F_{\mathrm{w}}$.

Let's assume that $F_{\mathrm{r}}=F_{\mathrm{fp}}$, then dependence (2) takes a form

$$
F_{0}+\pi\left(r_{\mathrm{s}}^{2}-r_{0}^{2}\right) \Delta p-G-g \bar{\delta} \rho_{\mathrm{w}} S_{\mathrm{fw}}-\pi r_{\mathrm{s}} H \rho_{\mathrm{w}} \bar{U}^{2} \cos \gamma=0
$$

Then taking into account the given dependences expression (8) will have an appearance

$$
\begin{aligned}
& -g \rho_{\mathrm{w}} S_{\mathrm{fw}}\left(\frac{3 v_{\mathrm{w}}^{2}}{4 g}\right)^{\frac{1}{3}}\left[\frac{4 \Gamma_{V}}{v_{\mathrm{w}}} \operatorname{Re}(1+\Pi)\right]^{\frac{1}{3}}-\frac{2 \pi r_{\mathrm{s}} \rho_{\mathrm{w}} \Gamma_{V}^{2} \cos \gamma}{H}= \\
& =0-g \rho_{\mathrm{w}} S_{\mathrm{fw}}\left(\frac{3 v_{\mathrm{w}}^{2}}{4 g}\right)^{\frac{1}{3}}\left[\frac{4 \Gamma_{V}}{v_{\mathrm{w}}} \operatorname{Re}(1+\Pi)\right]^{\frac{1}{3}}-\frac{2 \pi r_{\mathrm{s}} \rho_{\mathrm{w}} \Gamma_{V}^{2} \cos \gamma}{H}=0
\end{aligned}
$$

In case of supply of liquid on a normal to a longitudinal axis of the polymer bubble that usually takes place in practice, the component of a high-speed stream of a pressure of liquid becomes equal to zero. Then taking into account that $S_{\mathrm{fw}}=2 \pi r_{\mathrm{s}} L_{\mathrm{fw}}$ the equation of balance of forces (9) will finally take a form 


$$
\begin{aligned}
& -2 \pi r_{\mathrm{s}} \delta_{\mathrm{s}} \rho g\left(L_{\mathrm{fw}}+r_{\mathrm{s}} \operatorname{ctg} \frac{\beta}{2}\right)-2 \pi r_{\mathrm{s}} g \rho_{\mathrm{w}} L_{\mathrm{fw}}\left(\frac{3 v_{\mathrm{w}}^{2}}{4 g}\right)^{\frac{1}{3}}\left[\frac{4 \Gamma_{V}}{v_{\mathrm{w}}} \operatorname{Re}(1+\Pi)\right]^{\frac{1}{3}}= \\
& =0-2 \pi r_{\mathrm{s}} \delta_{\mathrm{s}} \rho g\left(L_{\mathrm{fw}}+r_{\mathrm{s}} \operatorname{ctg} \frac{\beta}{2}\right)-2 \pi r_{\mathrm{s}} g \rho_{\mathrm{w}} L_{\mathrm{fw}}\left(\frac{3 v_{\mathrm{w}}^{2}}{4 g}\right)^{\frac{1}{3}}\left[\frac{4 \Gamma_{V}}{v_{\mathrm{w}}} \operatorname{Re}(1+\Pi)\right]^{\frac{1}{3}}=0
\end{aligned}
$$

From dependence (10) define the value of volume cooling water concentration $\Gamma_{V}$, satisfying the condition of balance of forces (1) in the process of liquid cooling of the polymer bubble.

From dependence (10) critical values of volume cooling water concentration for tubular films of a different standard size from LDPE were defined. As in the specified dependence unknown sizes are both $\Gamma_{V}$, and $L_{\mathrm{fw}}$, which in turn depends on $\Gamma_{V}$, calculations carried out by method of consecutive approximations.

On critical values of volume cooling water concentration $\Gamma_{V}$ counted the volume productivity of the technological line $q$ (or the speed of an exit of polymer melt from the extrusion die $v_{0}$ ) from the condition of achievement of necessary temperature on an internal surface of the polymer bubble.

The nomogram for determination of volume cooling water concentration, and also volume productivity of the technological polymeric film line depending on geometrical parameters of a ready polymer bubble is given in Figure 3.

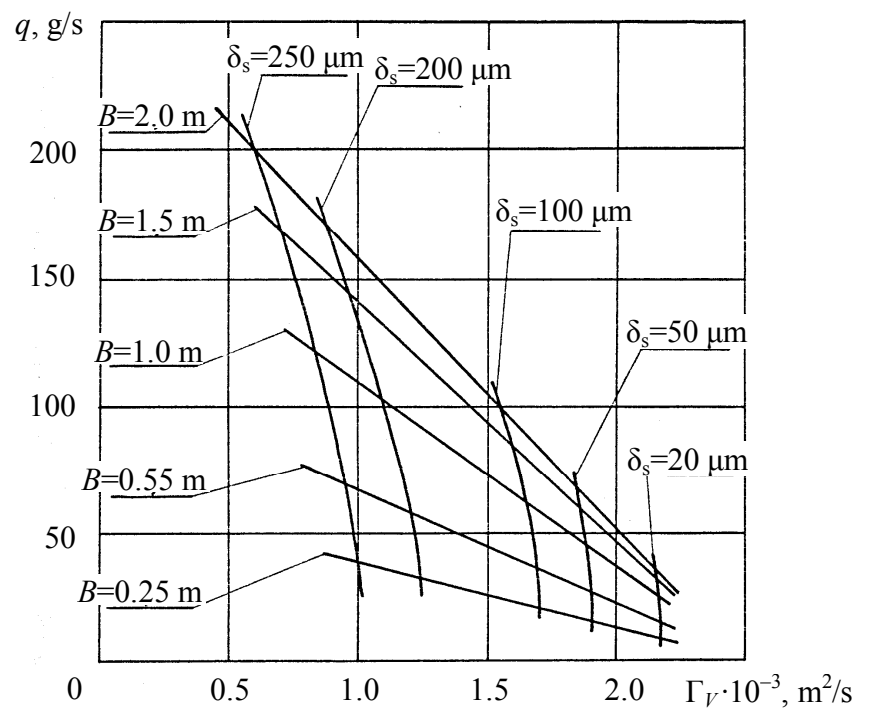

Figure 3. The nomogram for determination of extreme values of volume liquid concentration $G_{V}$ and productivity of the technological line $q$ from the geometrical sizes of the tubular blown polymeric film (film thickness $\delta_{\mathrm{K}}$ and width of polymer bubble in folded form $B$ )

As a result of theoretical researches of process of cooling of extruded tubular polymeric films with the flowing-down water film it is established that at the liquid concentration $\left(\Gamma_{V} \geq 5.03 \cdot 10^{-3} \mathrm{~m}^{2} / \mathrm{s}\right.$, or $\left.\operatorname{Re} \geq 20000\right)$ arise essential power load of the polymer bubble. Besides, at such high liquid concentration only the wall layer of liquid 
participates in heat exchange that leads to its over-expenditure.

Therefore when carrying out parametrical calculations it is necessary to define critical value of volume liquid concentration which can sustain the polymer bubble of a certain diameter and thickness.

Apparently from nomogram given on Figure 3, the greatest effect of liquid cooling can be reached at production of films with a width of the bubble in folded form to $1 \mathrm{~m}$.

\section{Experimental researches}

Parameters of processes of production of tubular blown films of LDPE (types 1 and 2) on experimental-industrial working plant are specified in Table 1.

Table 1

Parameters of processes of production of tubular blown films of LDPE of 1 type and type 2 (in brackets)

\begin{tabular}{|l|c|c|}
\hline \multicolumn{1}{|c|}{ Parameter } & $\begin{array}{c}\text { Unit of measure of } \\
\text { physical quantity }\end{array}$ & $\begin{array}{c}\text { Absolute value of physical } \\
\text { quantity }\end{array}$ \\
\hline Mass productivity of installation & $\mathrm{g} / \mathrm{s}$ & $\begin{array}{c}17.3-69.4 \\
(16.2-68.3)\end{array}$ \\
\hline $\begin{array}{l}\text { Speed of the movement of the } \\
\text { polymer bubble (stretching speed })\end{array}$ & $\mathrm{m} / \mathrm{s}$ & $0.07-0.5$ \\
\hline $\begin{array}{l}\text { Width of the polymer bubble in } \\
\text { folded form }\end{array}$ & $\mathrm{m}$ & $0.25 ; 0.5$ \\
\hline Thickness of the polymeric film & $\mathrm{mm}$ & $0.06-0.2$ \\
\hline $\begin{array}{l}\text { Melt temperature at the exit from an } \\
\text { extrusive die }\end{array}$ & ${ }^{\circ} \mathrm{C}$ & 180 \\
\hline $\begin{array}{l}\text { Volume consumption of the cooling } \\
\text { water }\end{array}$ & $10^{3} \mathrm{~m}^{3} / \mathrm{s}$ & $0.25-0.92$ \\
\hline Volume water concentration & $10^{3} \mathrm{~m}^{2} / \mathrm{s}$ & $0.35-0.88$ \\
\hline $\begin{array}{l}\text { Initial temperature of the cooling } \\
\text { water }\end{array}$ & ${ }^{\circ} \mathrm{C}$ & $20-60$ \\
\hline $\begin{array}{l}\text { Length of the zone of the continuous } \\
\text { current of the liquid film }\end{array}$ & $\mathrm{m}$ & $0.15-0.8$ \\
\hline $\begin{array}{l}\text { Width of the ring slot of water } \\
\text { supply }\end{array}$ & $\mathrm{m}$ & $0.4-0.8$ \\
\hline
\end{tabular}

Follows from table 1 that length of a zone of liquid cooling of the polymer bubble does not exceed $1 \mathrm{~m}$ while length of a zone of traditional air cooling of the polymer bubble can reach several meters [1].

Physical-mechanical properties of the tubular blown polymeric film from PEVD, type 2 , received at liquid cooling are given in Table 2 . 
Table 2

Physical-mechanical properties of the tubular blown polymeric film from LDPE, type 2

\begin{tabular}{|c|c|c|c|c|c|}
\hline \multirow{2}{*}{$\begin{array}{c}\text { Sample } \\
\text { No }\end{array}$} & \multicolumn{2}{|c|}{$\begin{array}{c}\text { Ultimate strength of the } \\
\text { film, MPa }\end{array}$} & \multicolumn{2}{|c|}{ Tensile strain, \% } & \multirow{2}{*}{$\begin{array}{c}\text { Temperature of } \\
\text { the cooling } \\
\text { water, }{ }^{\circ} \mathbf{C}\end{array}$} \\
\cline { 2 - 5 } & along & across & along & across & 20 \\
\hline 1 & 20.1 & 18.9 & 458 & 508 & 60 \\
\hline 2 & 20.6 & 18.5 & 432 & 500 & 40 \\
\hline 3 & 20.3 & 18.6 & 440 & 512 & 50 \\
\hline 4 & 19.8 & 18.1 & 453 & 497 & 60 \\
\hline 5 & 20.9 & 19.3 & 439 & 506 & \\
\hline
\end{tabular}

Further researches of cooling process of the film were conducted at a temperature of cooling water of $20{ }^{\circ} \mathrm{C}$ which corresponds to the average temperature of cold water in a water supply system.

Also influence of a ratio of length of the bubble blowing zone (distance $L_{\mathrm{ws}}$ from the extrusive die to the line of contact of cooling liquid with the polymer film bubble) and diameter of the bubble $D_{\mathrm{s}}$ on process of formation of the film on condition of ensuring stability and stability of liquid cooling was investigated.

It is shown that under a condition $L_{\mathrm{ws}} / D_{\mathrm{s}}<0.5$ on the bubble blowing zone has the parabolic form (a convex form), under a condition $0.5 \leq L_{\mathrm{ws}} / D_{\mathrm{s}} \leq 1,0-$ conic, and under a condition $L_{\mathrm{ws}} / D_{\mathrm{s}}>1.0$ - the neck is formed (a concave form). At the same time it is proved that the bubble with a parabolic form blowing zone the steadiest, and the films received thus are characterized by a minimum of anisotropy of properties.

Results of researches of physical-mechanical properties of the tubular blowing film at the following data are given in Table 3: diameter $-350 \mathrm{~mm}$, blowing degree -1.4 , the mass productivity of the extruder $-16 \mathrm{~g} / \mathrm{s}(57.6 \mathrm{~kg} / \mathrm{h})$. Apparently from tab. 3 , length of the blowing zone (or the ratio $L_{\mathrm{ws}} / D_{\mathrm{s}}$ ) insignificantly influences physical-mechanical properties of the produced film, however, as it was specified, with increase $L_{\mathrm{ws}} / D_{\mathrm{s}}$ stability of process of a shaping of the film is broken.

Table 3

Physical-mechanical properties of the film depending on length of a blowing zone

\begin{tabular}{|c|c|c|c|c|}
\hline \multirow{2}{*}{$L_{\text {ws }} / D_{\mathrm{s}}$} & \multicolumn{2}{|c|}{ Ultimate strength of the film, MPa } & \multicolumn{2}{c|}{$\begin{array}{c}\text { Tensile strain, } \\
\%\end{array}$} \\
\cline { 2 - 5 } & along & across & along & across \\
\hline 0.343 & 22.7 & 22.5 & 750 & 775 \\
\hline 0.429 & 22.1 & 22.0 & 762 & 785 \\
\hline 0.600 & 22.8 & 22.6 & 770 & 735 \\
\hline 0.857 & 21.0 & 22.1 & 745 & 780 \\
\hline
\end{tabular}

Results of numerical modeling of process of cooling of the tubular blown polymeric film with the flowing-down film of liquid [31] showed satisfactory compliance to data of experimental researches. 


\section{Conclusion}

The following conclusions can be drawn, based on the obtained results:

1. Parameters of the liquid film (a speed profile, film thickness) change only on an entrance zone and depend on density of liquid concentration of the polymer bubble and initial distribution of speed of the liquid film at the exit from a distributive ring.

2. At the high values of liquid concentration providing the developed turbulent mode of a current of the liquid film (Reynolds number over 20000), only the wall layer of liquid participates in heat exchange.

3. For the film from LDPE its external surface hardens at distance about $0.01 \mathrm{~m}$ from the beginning of contact with water, and an internal surface - at distance about $0.10-0.15$ $\mathrm{m}$. Therefore the ring for distribution of liquid needs to be established after the termination of a blowing zone of the polymeric tubular workpiece. It is also necessary to provide the steady movement of a continuous liquid film on an external surface of a polymeric tube on length to $0.2 \mathrm{~m}$ from the beginning of contact of liquid from the polymeric film.

4. For thick films from LDPE (thickness more than $200 \mu \mathrm{m}$ ) and over $1 \mathrm{~m}$ wide intensity of cooling is limited to the critical liquid concentration.

5. For practical application of the received results the nomogram for determination of volume liquid concentration of the cooling water, and also volume productivity of the technological line depending on the sizes of a ready tubular blown polymeric film is offered.

6. Temperature of the cooling water in the range of $20-60{ }^{\circ} \mathrm{C}$ significantly does not influence both intensity of cooling process, and physical-mechanical properties of the produced polymeric film.

7. Extreme values of degree of the polymer bubble blowing $\left(K_{\mathrm{b}}=2\right)$ and degree of stretching $\left(K_{\mathrm{s}}=4\right)$ from LDPE are established. It is shown that the limiting stage in production of thin films (thickness of $40 \mu \mathrm{m}$ and less) with a speed of receiving not less than $0.5 \mathrm{~m} / \mathrm{s}$ is not process of cooling, and physical-mechanical properties of the film (in particular anisotropy of its properties).

The obtained results of researches allow to determine rational parameters of technological processes of producing tubular blown polymeric films.

\section{References}

1. Lukach Yu. E., Petuhov A. D., Senatos V. A. (1981), Oborudovanie dlya proizvodstva polimernykh plenok, Equipment for production of polymeric films, Mashinostroenie, Moscow (in Russian).

2. Tadmor Z., Gogos C. G. (2006), Principles of polymer processing, John Wiley \& Sons, Inc., New Jersey.

3. Rauwendaal C. (2014), Polymer extrusion, Carl Hanser Verlag, Munich, DOI: $10.3139 / 9781569905395$

4. Mikulionok I. O. (2015), Classification of Processes and Equipment for Manufacture of Continuous Products from Thermoplastic Materials, Chemical and Petroleum Engineering, 51(1-2), pp. 14-19, doi: 10.1007/s10556-015-9990-6 
5. Mikulionok I. O., Radchenko L. B. (2012), Screw extrusion of thermoplastics: I. General model of the screw extrusion, Russian Journal of Applied Chemistry, 85(2), pp. 489-504, doi: $10.1134 / \mathrm{s} 1070427211030305$

6. Mikulionok I. O., Radchenko L. B. (2012), Screw extrusion of thermoplastics: II. Simulation of feeding zone of the single screw extruder, Russian Journal of Applied Chemistry, 85(3), pp. 505-514, DOI: 10.1134/s1070427211030317

7. Mikulionok I., Gavva O., Kryvoplias-Volodina L. (2018), Modeling of melting process in a single screw extruder for polymer processing, Eastern-European Journal of Enterprise Technologies, 2/5(92), pp. 4-11, DOI: 10.15587/1729-4061.2018.127583

8. Mikulionok, I. O. (2013), Screw extruder mixing and dispersing units, Chemical and Petroleum Engineering, 49(1-2), pp. 103-109, DOI: 10.1007/s10556-013-9711-y

9. Vytvytskyi V., Mikulionok I., Sokolskyi O., Gavva O. (2017), Pressure and temperature influence on the friction coefficient of granular polymeric materials on the metal surfaces, Ukrainian Food Journal, 6(3), pp. 543-552, DOI: 10.24263/2304-974X-2017-6-3-14

10. Shin D. M., Lee J. S., Jung H. W., Hyun J. C. (2007), Multiplicity, bifurcation, stability and hysteresis in dynamic solutions of film blowing process, Journal of Rheology, 51(4), pp. 605-621, DOI: $10.1122 / 1.2736405$

11. Kashyap M. J., Ghosh A. K. (2013), Processing, rheology and characterization of polypropylene nanocomposites and their blown films, Journal of Plastic Film and Sheeting, 29(3), pp. 228-248, doi: 10.1177/8756087912473099

12. Khonakdar H. A., Morshedian J., Nodehi A. O. (2002), Mathematical and Computational Modeling of Heat Transfer and Deformation in Film Blowing Process, Journal of Applied Polymer Science, 86(9), pp. 2115-2123, DOI: 10.1002/app.10769

13. Hong Y., Coombs S. J., Cooper-White J. J., Mackay M. E., Hawker C.J., Malmström E., Rehnberg N. (2000), Film blowing of linear low-density polyethylene blended with a novel hyperbranched polymer processing aid, Polymer, 41(21), pp.7705-7713. DOI: 10.1016/S0032-3861(00)00130-0

14. Wang W., Zhang H., Jia R., Dai Y., Dong H., Hou H., Guo Q. (2017), High performance extrusion blown starch/polyvinyl alcohol/clay nanocomposite films, Food Hydrocolloids, 79, pp. 534-543, DOI: 10.1016/j.foodhyd.2017.12.013

15. Thunwall M., Kuthanová V., Boldizar A., Rigdahl M. (2008), Film blowing of thermoplastic starch, Carbohydrate Polymers, 71(4), pp. 583-590, DOI: 10.1016/j.carbpol.2007.07.001

16. Zullo R., Iannace S. The effects of different starch sources and plasticizers on film blowing of thermoplastic starch: Correlation among process, elongational properties and macromolecular structure, Carbohydrate Polymers, 77(2), pp. 376-383, DOI: 10.1016/j.carbpol.2009.01.007

17. La Mantia F. P., Ceraulo M., Mistretta M. C., Morreale M. (2018), Rheological Behaviour, Mechanical Properties and Processability of Biodegradable Polymer Systems for Film Blowing, Journal of Polymers and the Environment, 26(2), pp. 749-755, DOI: 10.1007/s10924-017-0995-4

18. Mallegni N., Phuong T. V., Coltelli M.-B., Cinelli P., Lazzeri A. (2018), Poly(lactic acid) (PLA) Based Tear Resistant and Biodegradable Flexible Films by Blown Film Extrusion, Materials, 11(1), pp. 148-163, DOI:10.3390/ma11010148

19. Singh S., Gupta R. K., Ghosh A. K., Maiti S. N., Bhattacharya S. N. (2010), Poly (L-lactic acid)/layered Silicate Nanocomposite Blown Film for Packaging Application: Thermal, Mechanical and Barrier Properties, Journal of Polymer Engineering, 30(5-7), pp. 361-376, DOI:10.1515/POLYENG.2010.30.5-7.361

20. Zhang X.M., Elkoun S., Ajji A., Huneault M.A. (2003), Oriented structure and anisotropy properties of polymer blown films: HDPE, LLDPE and LDPE, Polymer, 45(1), pp. 217229, DOI: $10.1016 /$ j.polymer.2003.10.057 
21. Micic P., Bhattacharya S. N. (2000), Rheology of LLDPE, LDPE and LLDPE/LDPE blends and its relevance to the film blowing process, Polymer International, 49(12), pp. 15801589, DOI: 10.1002/1097-0126(200012)49:12<1580::AID-PI547>3.0.CO;2-Q

22. Münstedt H., Kurzbeck S., Stange J. (2006), Importance of elongational properties of polymer melts for film blowing and thermoforming, Polymer Engineering and Science, 46(9), pp. 1190-1195, DOI: 10.1002/pen.20588

23. Kolarik R., Zatloukal M. (2013), Evaluation of Variational Principle Based Model for LDPE Large Scale Film Blowing Process, AIP Conf. Proc., 1526, pp. 119-127, DOI: $10.1063 / 1.4802607$

24. Lamnawar K., Maazouz A., Cabrera G., Al-Itry R. (2018), Interfacial Tension Properties in Biopolymer Blends: From Deformed Drop Retraction Method (DDRM) to Shear and Elongation Rheology-Application to Blown Film Extrusion, International Polymer Processing, 33(3), pp. 411-424, DOI: 10.3139/217.3614

25. Mallet, B., Lamnawar, K., Maazouz, A. (2014), Improvement of Blown Film Extrusion of Poly(lactic acid): Structure-Processing- Properties Relationships, Polymer Engineering and Science, 54(4), pp. 840-857, DOI: 10.1002/pen.23610

26. Lee J. S., Jung H. W., Hyun J. C. (2011), Transient solutions of nonlinear dynamics in film blowing process accompanied by on-line crystallization, Journal of Rheology, 55(2), pp. 257-271, DOI: 10.1122/1.3532091

27. Muslet I. A., Kamal R. (2004), Computer simulation of the film blowing process incorporating crystallization and viscoelasticity, Journal of Rheology, 48(3), pp. 525-550, DOI: $10.1122 / 1.1718500$

28. Oliviero M., Di Maio E., Iannace S. (2010), Effect of molecular structure on film blowing ability of thermoplastic zein, Journal of Applied Polymer Science, 115(1). pp. 277-287, DOI: 10.1002/app.31116

29. Mikulionok I.O. (2012), Modeling of the Heat Processing of Continuously Molded Product, Russian Journal of Applied Chemistry, 85(9), pp. 1482-1492, DOI: $10.1134 / \mathrm{S} 1070427212090285$

30. Mikulionok I., Gavva O., Karvatskii A., Yakymchuk M. (2017), Modeling and analysis of the process of polymeric film cooling on the drum with a liquid cooling agent, EasternEuropean Journal of Enterprise Technologies, 5/5(89), pp. 67-74, DOI: 10.15587/17294061.2017.110687

31. Mikulionok I.O., Radchenko L.B. (2011), Simulation of Liquid Cooling of an Extruded Sleeve Plastic Film, Russian Journal of Applied Chemistry, 85(6), pp. 1080-1084, DOI: 10.1134/S1070427211060334

32. Petrenko V., Pryadko M.,Zasyadko Ya., Miroshnyk M. (2016), Modeling of heat transfer in free down flowing laminar liquid films with development wavy structure at the regime of evaporation from the interface, Ukrainian Food Journal, 5(1), pp. 162-173.

33. Wong H. Y. (1977), Handbook of Essential Formulae and Data on Heat Transfer for Engineers, Longman Group, Ltd., London.

34. Gapon V.S. (1982), Issledovanie protsessa proizvodstva plyonok iz termoplastov s zhidkostnym okhlazhdeniem, Research of production process of films of thermoplastics with liquid cooling, Thesis of Candidate of Technical Sciences, Kyiv (in Russian). 